

\title{
Mapping Worlds: Frames of Reference in MalakMalak
}

\author{
DOROTHEA HOFFMANN \\ University of Chicago
}

\section{Introduction*}

This paper presents an analysis of spatial language, in particular, 'Frames of Reference' (FoR) utilizing elicitation, stimuli and natural discourse in fieldwork settings. The language in question is MalakMalak, a non-Pama-Nyungan Northern Daly language with eleven identified remaining speakers mainly based in the Daly River Region in Australia.

\subsection{The language and its speakers}

MalakMalak is spoken in the Aboriginal communities of Woolianna on the Daly River, Peppimenarti, Belyuen, Fifteen-Mile, and Bagot in the Northern Territory of Australia. Almost all speakers are also fluent in at least the Daly variety of Kriol as well as Matngele, a related Eastern Daly Language.

\footnotetext{
*I would like to gratefully acknowledge financial support from the Franklin Research Grant of the American Philosophical Society and the Endangered Languages Documentation Program IPF0189 allowing me to spend a total of over 9 months in Woolianna and surrounding areas between May 2012 and September 2013. The data collected during this fieldwork, some field recordings made between 2009 and 2012 generously shared by Mark Crocombe, and a collection of elicitation and communicative discourse material collected between 1971 and 1973 unconditionally made available by David Birk and obtained from AIATSIS in Canberra, form the basis of this study. Furthermore, I would like to specifically thank Biddy Yingguny Lindsey, Frances Mijat, Rita Pirak, Rita McGregor, Rosie Mary Magdalene Kabat, Barbara Tenblin, Michael Kunbuk, Don White, and Edward Andrews for generously sharing their knowledge of MalakMalak with me. Additional thanks go to Rob Lindsey and Joye Maddison for supporting my work with the MalakMalak people in every respect.
} 


\section{Dorothea Hoffmann}

\subsection{Frames of Reference, Deixis and Cognition}

Studies into FoR systems provide insight into the relationship between language and cognition, and highlight how landscape features are reflected in language use and vice versa. They have been widely discussed from a cross-linguistic perspective. This includes the 'classic' three-part distinction between intrinsic, relative, and absolute FoR (Levinson, 2003; Pederson et al., 1998; Levinson, 1996). Additionally, some authors have argued to incorporate deixis (Danziger, 2003; 2010; Bickel, 2001; Burenhult, 2008) and gesture (Haviland, 1993) into the typology. Also, the notion of 'Orientation' (Terrill and Burenhult, 2008) accounts for instances where intrinsic facets of a figure are oriented in relation to a reference object ${ }^{1}$. Finally, Bohnemeyer and O'Meara (2012) claim that anchoringtypes and vectors in particular provide a significant link between FoR and 'orientation' within FoR typology. Bohnemeyer (2013) furthermore argues that the use of a particular FoR can be diffused through language contact.

This paper aims to provide a detailed description of MalakMalak's Frame of Reference system addressing the intricate relationship between language, culture, landscape, and cognition described by one speaker as 'The language is like a map.'

\section{Frames of Reference in MalakMalak}

All observations of MalakMalak's previously undocumented FoR system result from nine months of fieldwork between 2012 and 2013. The collected data comes from elicitation stimuli such as the 'Men \& Tree' (M\&T) task (Levinson et al., 1992), the 'Ball \& Chair' (B\&C) task (Bohnemeyer and Perez Baez, 2008), and examples from narrative and conversational discourse environments.

All three 'classic' FoR types are employed. There are distinct lexical items used for vertical intrinsic (jalk/karrarra 'underneath/on top of') and absolute FoR (puyunduk/kanjuk 'down/up'), and the same lexemes are used in relative and intrinsic FoR denotations (elimirri/angundu 'in front/behind'; yanbarr/jalmiyen 'left/right'). There is a cardinal-type system based on the directions of prevailing winds blowing from the sea ( $\mathrm{nul}$ ) and inland (dangid) and a solar-system utilizing directions of the setting (miri jalk) and rising sun (miri baiga).

Deictic terms are used to denote proximal (kinangga) and distal (ngunanggi) space over a boundary. This distinction has furthermore been conventionalized to

\footnotetext{
${ }^{1}$ The terminology in this paper follows Talmy's $(1985,2007)$ distinction between a Figure (the object to be located) and a Ground (the object in relation to which the figure is located). For examples involving 'orientation', I maintain Terril and Burenhult's (2008) terminology of distinguishing between a ground (in FoR) constructions and a reference object (in orientation settings).
} 
encode the respective riverbanks of the Daly River ('northeastern/southwestern bank'). Additionally, related demonstratives are used with proximal (ki/kinanggi 'here/this side') and distal (ngun/ngunanggi 'there/that side') meanings.

Finally, two contrasting terms keen and kaduk are accompanied by pointing gestures, denoting not strictly proximity, but person-based reference and a contrast of 'here' and 'there' space.

\subsection{Strategies of spatial reference}

Speakers freely switch between intrinsic (1) and (2) relative frames showing no clear preference for either.

(1)

$\begin{array}{lll}\text { tyung } & \text { angundu-na } & \text { muyu } \\ \text { tree } & \text { behind-LOC } & \text { 3SG.NEU.stand.PST }\end{array}$

'the tree stood behind (the man)'(DH12_A23_07.145)

(2) yerra jalmiyiny dek kanjuk purrat-ma wuta PART right/straight place up jump-CONT 3SG.NEU.go.PST 'now (the ball) is on the right, jumping up (lit. jumping continuously in an upward place)' (DH12_A43_03.105)

(3) Example of (1)



(4) Example of (2)

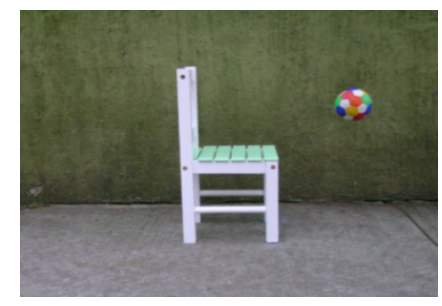

Various body-part terms are used to orient figures with relation to reference objects (5), cardinal directions, or toponyms and result in noun incorporation with the complex predicate ${ }^{2}$. If no reference object is specifically named, the orientation of the figure is by default interpreted deictically.

(5) tyed mel-yen wuyu stand calf-DIR 3SG.NEU.stand.PRES

'(the ball) is towards the calf (of the chair)' (DH12_V44_02_047)

MalakMalak employs two types of specialized terms for vertical intrinsic (6) and absolute FoR (7).

\footnotetext{
${ }^{2}$ This is furthermore illustrated by varied word-order within the complex predicate in example (5).
} 


\section{Dorothea Hoffmann}

(6) dudyur-eli

jalk ali wuyu

cause.lie-PART underneath leg 3SG.NEU.stand.PST

'it is lying in an angle from the legs, underneath (the chair)' (DH12_A43_03.114)

(7) kinangga wuyu, puyunduk-na

PROX.side 3SG.NEU.stand.PST down-LOC

'(the ball is) on this side, below/down' (DH12_A43_02.104-5)

(8) Example of (6)

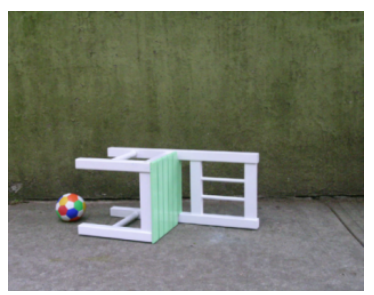

(9) Example of (7)

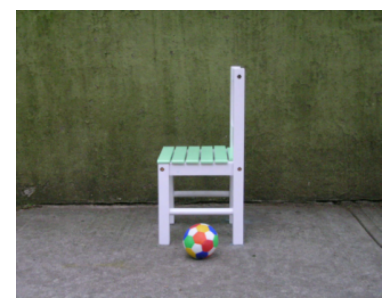

This has also been observed elsewhere. In Roper Kriol, adverbial suffixes and prepositions -ap/dan 'up/down' are used in absolute FoR only, while the adverbs ontop/andanith 'on top/underneath' only occur in intrinsic encodings (Hoffmann, 2011: 108-110) and in Jaminjung absolute terms are converted into intrinsic ones by ablative suffixes (Schultze-Berndt, 2006: 107).

Some of the pictures in the M\&T stimuli task lack grounds within the picture setup as seen in (11). Then, speakers often make use of a set of horizontal absolute directional terms based on the direction of prevailing winds in the wet ( $n u l$ 'northwesterly') and dry season (dangid 'southeasterly'), as well as the rising (miri baiga) and setting of the sun (miri jalk). Orientation may be explicitly expressed in a body-part term or more implicitly in a directional case-suffix (10).

(10) nul-yen

$w u d y u=w e$

northwesterly-DIR

3PL.stand.PST $=$ FOC?

'they stood towards the northwesterly wind direction'

(DH12_A15_03.012)

(11) Stimuli setup for (10).

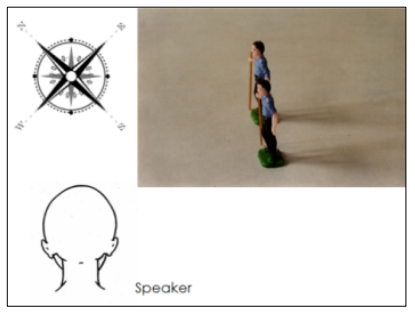


Both types of directionals are used independent of season or time of day and may therefore be considered 'absolute' and abstracted in par with Levinson (2003). The map in (12) illustrates the directionals.

(12) Absolute directionals in MalakMalak

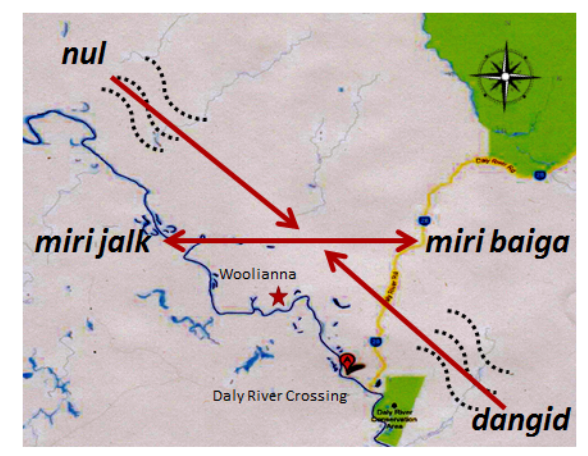

Speakers also often choose named places to orient figures in space as shown in (13). These types of expressions are, like absolute directionals, only used in orientation, but not location settings.

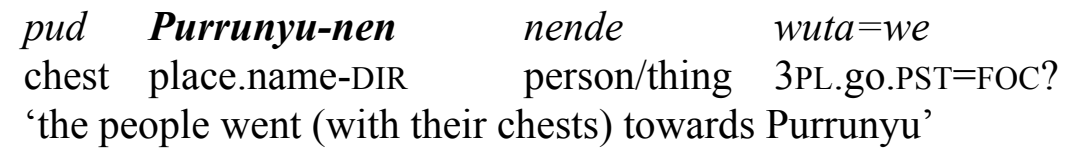
(DH12_A15_03.183)

\subsection{Deixis and referencing}

In addition to intrinsic, relative and absolute terms, MalakMalak makes extensive use of deictics and demonstratives in spatial description. A system of boundarybased proximal and distal location (kinangga/ngunanggi) has been conventionalized to denote the respective riverbanks of the Daly River as seen in (14). The traditional lands of the MalakMalak were located on both sides of the Daly River in the past, the majority of their settled land, however, used to lie on the kinangga side (Stanner, 1933; Birk, 1976).

(14) The riverbank system

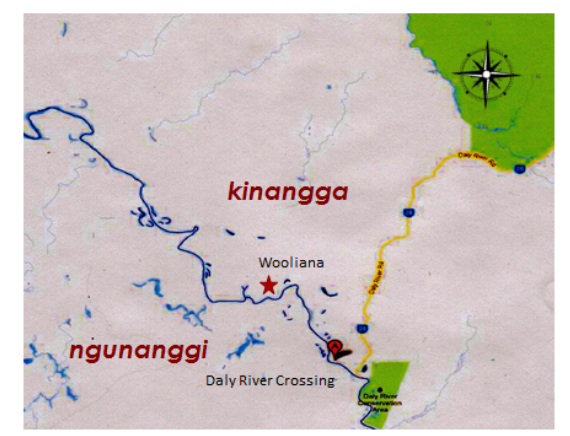




\section{Dorothea Hoffmann}

The terms are used deictically and mostly maintain absolute orientation to the riverbanks. In (15), in response to the setup in (16) below, the speaker is facing the river which is close, but not visible. The figure (the toy man) is described as orienting itself towards the speaker and as being ngunanggi. The lexeme depicts a location on the 'other' side using the gathered toy pigs as a dividing item. However, the 'absolute' direction of ngunanggi in relation to the river itself from the speaker's deictic center is still maintained.

$\begin{array}{ll}\text { ngunanggi-many } & \begin{array}{l}\text { pudang } \\ \text { other.side/southwestern.bank-ABL }\end{array} \\ \text { chest.give }\end{array}$

tyedali yuyu

stand.CONT 3SG.masc.stand.PRES

'he is facing (towards me) from the other side' (DH12_A15_04.086)

(16) Stimuli setup for (15)

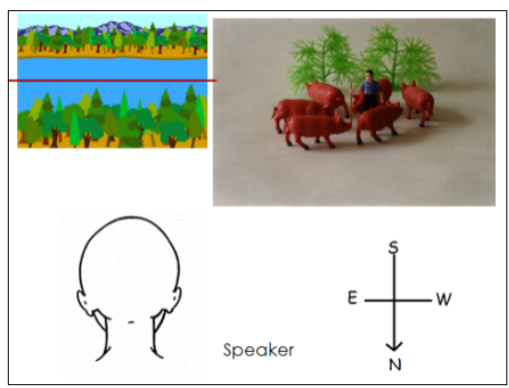

Maintaining this absolute orientation with respect to the riverbank may sometimes override the original deictic meaning of the terms. In (17) below, the speaker refers to the absolute locations denoted by the term kinangga. The location of the ball as shown in (18) is described as being on the kinangga side. Here, this relates to a location on the other side of the chair and is thus separated by it from the speaker. In absolute terms, however, the ball is located towards the kinangga side of the river, the same way the speaker is facing.
(17) duk puyunduk kinangga yide chair=we place underneath northeastern.bank 3SG.masc.go.PRES chair $=$ FOC 'it goes underneath, on this side of the chair' (DH12_V44_04.103)

This type of pattern where a deictic contrast may also involve geographical or environmental features has also been described for Dyirbal, which employs demonstrative modifiers contrasting upriver/downriver distinctions with uphill/downhill ones (Anderson and Keenan, 1985; Dixon, 2003: 85). 
(18) Stimuli setup for (17)

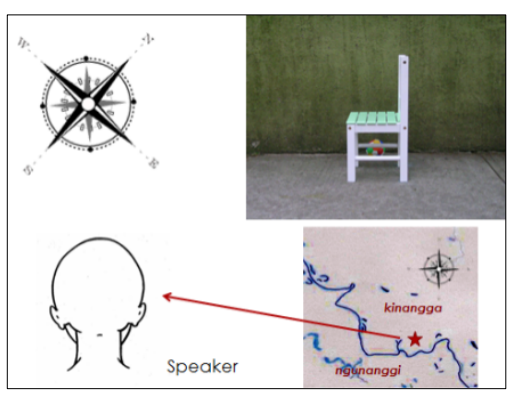

A closer look at the usage patterns for these riverbank terms reveals a tight connection between the place of utterance and denoting deictic vs. absolute location. In my collection of M\&T as well as B\&C recordings, I could only find one instance of absolute usage of speakers outside of Woolianna and at the same time only one example of a deictic use without maintaining the river reference for speakers within Woolianna. This suggests that the transition from deictic to absolute may be directly linked to movement patterns and resettlement of MalakMalak speakers outside their traditional homelands.

As I have shown above, these terms then, for the Woolianna location, are not abstract and fixed in Levinson's (2003) sense. Instead, they denote concrete directions bound to the landscape and a non-abstracted course of the river. This represents evidence for the type of close-knit relationship between the geomorphic features of the traditional lands and language use by its speakers.

Additionally, there are distal and proximal demonstratives derived from kinangga and ngunanggi. In (19) the location of the sticks the two toy men hold is encoded in the deictic term kinanggi and refers to the side the speaker is located on.

(19)

$\begin{array}{llll}\text { wangarri } & \begin{array}{l}\text { kinanggi } \\ \text { 2SG }\end{array} & \text { pud jalmiyen } \\ \text { this.side } & \text { chest } & \text { right.hand }\end{array}$

'to you (referring to the matcher in the Men \&Tree game) (they are oriented), (the stick is) on this side (towards me, with the chest to the right)' (DH12_A24_02.089)

(20) Stimuli setup for (19)

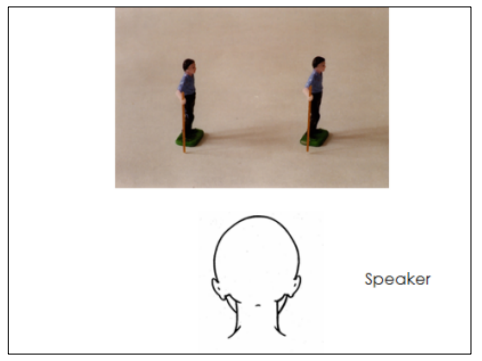




\section{Dorothea Hoffmann}

The deictic terms may be analyzed as exemplified in (21) below. Birk (1976: 87-88) describes two (albeit verbal) deictic suffixes that denote movement or orientation towards (-nggi) and away from the deictic center (-ngga). This kind of split semantic analysis only holds true for the abstracted deictic terms, but not for the absolute riverbank terms. The interpretation is also overturned if explicit body-part terms are used to orient the figure.

\begin{tabular}{|c|c|c|c|c|c|}
\hline ngun & $-a n$ & $-n g g i$ & ngun & $-a n$ & $-n g g a$ \\
\hline \multicolumn{3}{|c|}{$\begin{array}{l}\text { 'being in a distant location } \\
\text { orienting/moving towards the deictic } \\
\text { center' }\end{array}$} & \multicolumn{3}{|c|}{$\begin{array}{l}\text { 'being in a distant location } \\
\text { orienting/moving away from the } \\
\text { deictic center' }\end{array}$} \\
\hline$k i$ & $-a n$ & $-n g g i$ & $k i$ & $-a n$ & $-n g g a$ \\
\hline \multicolumn{3}{|c|}{$\begin{array}{l}\text { 'being in a proximal location } \\
\text { orienting/moving towards the deictic } \\
\text { center' }\end{array}$} & \multicolumn{3}{|c|}{$\begin{array}{l}\text { 'being in a proximal location } \\
\text { orienting/moving away from the deictic } \\
\text { center' }\end{array}$} \\
\hline
\end{tabular}

Finally, ngun and $k i$ are demonstratives denoting distance in terms of general visibility (proximity) and invisibility (distance) as in (22) only, as similarly observed for Yucatec Maya (Hank, 1990).

$\begin{array}{llll}\boldsymbol{k i} \text {-man } & \text { pi-ma } & \text { wutangga } & \text { ngun } \\ \text { PROX-ABL } & \text { move-CONT } & \text { 3PL.go.PURP } & \text { DIST } \\ \text { anu } & \text { purrarr } & & \\ \text { 1SG.EXCL.sit.PST } & \text { go.round } & & \end{array}$

'from here where I sat, the water goes and becomes whirly (500 m away and invisible)' (DH12_A15_04.321)

(23) Terms along the deictic continuum

\begin{tabular}{|llll|}
\hline \multicolumn{2}{|c|}{ Proximal } & & Distal \\
\hline$k i$ & 'here/this one' & ngun & 'there/that one' \\
\hline kinanggi & 'this side' & ngunangga & 'that side' \\
\hline kinangga & 'this side closer to me, & ngunanggi & 'that side away from \\
& $\begin{array}{l}\text { northeastern } \\
\text { riverbank' }\end{array}$ & $\begin{array}{l}\text { me, southwestern } \\
\text { riverbank' }\end{array}$ \\
\hline
\end{tabular}

This type of 'boundary' deixis has also been described for other languages. In Cherokee a pair of verbal prefixes attaches to dynamic and static event utterances 


\section{Mapping Worlds: Frames of Reference in MalakMalak}

and encodes locations within and outside a visible/experienced environment (Koops, 2013) which may be analyzed as a deictic boundary-based distinction ${ }^{3}$.

Another example involves the Bantu language Mushunguli which has a set of three locative prefixes that attach to nouns in referential expressions (Barlew, 2016). Finally, in Belhare, a system of demonstratives encodes conceptual boundaries in spatial discourse and in a social/cultural context where the concept of 'boundary' is a significant rhetorical device (Bickel, 2001: 241).

The demonstratives ki/ngun refer to space in the general vicinity or distance to the speaker. They are never used in orientation settings. Boundary-related terms, on the other hand, denote specific locations.

Haviland (1993: 10) observes that in his corpus of Guugu Yimithirr 60\% of all cardinal direction tokens co-occur with inflected forms of such explicit deictic elements as 'here', 'this', 'there', 'that', 'come' and 'go'. This high proportion suggests that cardinal directions are anchored in the same ways as deictics. In MalakMalak, for absolute terms based on the course of the sun, a similarly high proportion (57\%) occurred with deictic terms. This hints at a correlation between absolute terms and deictic anchoring as observed for Guugu Yimithirr. Interestingly, this kind of correspondence was not found for the other absolute term pair nul/dangid. Only $16 \%$ of tokens co-occurred with deictic terms while the riverbank lexemes kinangga/ngunanggi (if used absolutely) were never accompanied by deictic terms. These observations suggest that the wind-based terms function differently from the ones based on the sun in terms of anchoring. When accompanied by deictics, the sun-terms are more often anchored in the speech situation in denoting the time of day with regards to light situations and time references. The wind-terms, on the other hand, are independent of current wind directions at the time of utterance. Additionally, the absence of riverbank terms with deictic elements suggests that these are inherently deictic themselves which allows for the type of meaning abstraction from deictic to absolute described above.

\subsection{On the interplay of gesture and spatial reference}

There are two deictic lexemes which may act as discourse markers to establish a space within which speakers interact and/or which speakers converse about. These denote specific locations mostly accompanied by gesturing. While kaduk 'DIST' occurs in opposition to keen 'PROX' only, keen may also act as a kind of discourse marker placing the narrative space in the here and now. In (24) the term is accompanied by a gesture and draws the orientation of the toy figure from the speech situation towards the direction of the named place that serves as the reference object in this spatial setup. Burenhult (2008: 109-110) argues that

\footnotetext{
${ }^{3}$ Eve Danziger suggested this kind of parallel distinction during the discussion section of the paper given at BLS39 which followed the author's own presentation on MalakMakak.
} 


\section{Dorothea Hoffmann}

coordinate systems invoked by demonstratives involve the projection of a search domain from the deictic center (the ground) along the axial asymmetry in order to relativize the referent (the figure). These asymmetries can be fully abstract (cardinals), or locally dependent on geophysical features (e.g. river profile). This kind of analysis is underlined by findings in MalakMalak and extends the semantic range of demonstratives to stretch from directional to deictic meanings.

\begin{tabular}{|c|c|c|c|}
\hline$k i=w e$ & keen-en & pudang & tyedali \\
\hline $\begin{array}{l}\text { PROX=FOC? } \\
\text { yuyu }\end{array}$ & PROX-DIR & $\begin{array}{l}\text { chest.give } \\
\text { Wag Purrarr }\end{array}$ & stand.CONT \\
\hline 3SG.MASC.st & Ad.PRES & place.name & \\
\hline
\end{tabular}

Examples (25) and (26) occurred in the same recording session in succession to one another and are descriptions of the same stimuli picture by two different speakers in a setup visualized in
nen kagak muyu keen-en
thing/person far 3SG.NEU.stand.PST PROX-DIR
'the ball was far away (from the chair) (standing) towards here'
(DH12_V44_02.298, speaker RP)

(26) kaduk-en muyu

DIST-DIR 3SG.NEU.stand.PST

'the ball stood towards there' (DH12_V44_02.299, speaker BL)

(27) Stimuli setup for (25) and (26)

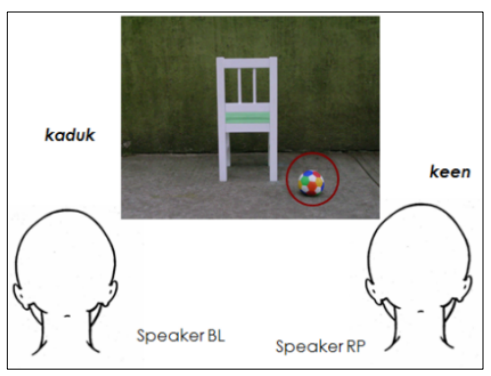

While RP in (25) describes the location of the ball as being in a location proximal to herself with keen, speaker BL in (26) responds to this with kaduk to indicate that the ball is in a location away from herself and towards RP. This indicates that these terms also encode a type of person deixis ${ }^{4}$ where keen denotes

\footnotetext{
${ }^{4}$ Thanks are owed to Eve Danziger pointing out this possibility to me.
} 


\section{Mapping Worlds: Frames of Reference in MalakMalak}

a location close to first person and kaduk to second person singular in a speech situation. Such a system has been described for Mopan Maya (Danziger, 1994). Another option (viable in situations with only one speaker) is the type of spatially elastic and contextually and pragmatically dependent perimeter anchored in the speaker as 'here-space' (keen) and 'there-space' (kaduk) (Enfield, 2003).

In discourse ${ }^{5}$, these terms are accompanied by directed pointing ${ }^{6}$ and gesturing. Example 0 is a direct speech act from a traditional narrative about a Tree Monitor that asks the Blue-Tongue Lizard to join him in his hole to seek shelter from a King Brown snake. Since the speaker is impersonating the Tree Monitor's speech at the moment of utterance, the location of the hole is with her and this is also where she is pointing at in a repeated downward motion of the hand with the fingers oriented downwards. In example 0 on the other hand, the speaker replies to a question the researcher has just asked about the location of a dreaming place where the story about a dingo and a Ladybug eating cheeky yam is taking place. Here, she points in the absolute direction of ngunanggi (the southwestern riverbank) and a location at quite some distance from the utterance location. Her fingers are pointed and a flicking movement of the hand furthermore indicates a relatively greater distance of the place described.

$\begin{array}{llccc}\text { dim } & \text { keen nga-na } & \text { tyurrk } & \text { pakang } & \text { nunguny } \\ \text { hole } & \text { PROX 1SG.EXCL-ALL } & \text { go.inside } & \text { sit.give } & \text { 2SG.go.IMPF }\end{array}$
'you are coming and sitting down here with me in my hole' (DH12_V36_05.085)

(29) Speaker orientation and gesture for (28)

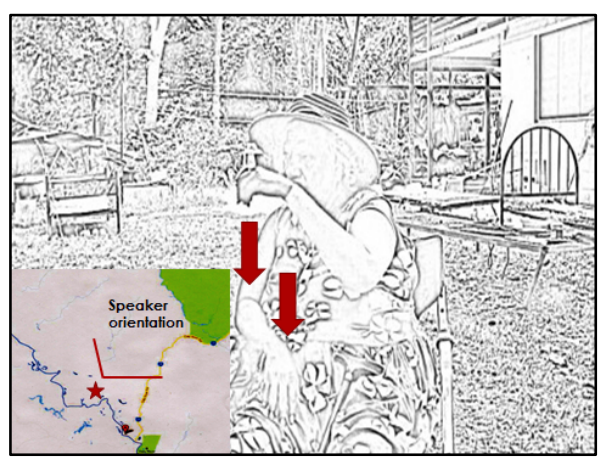

\footnotetext{
${ }^{5}$ From memory and fieldnotes, pointing also accompanies these terms in stimuli setups such as the $\mathrm{B} \& \mathrm{C}$ game with kaduk usually accompanied by a continuous gesture indicating greater distance and keen supported by smaller gestures indicating proximity. However, I do not have any videorecordings to confirm these observations at the time of writing.

${ }^{6}$ In fact, kaduk might be seen as a being semantically similar to what Bickel (2001:234) describes in Belhare for the term ina which is semantically restricted to distal pointing.
} 


\section{Dorothea Hoffmann}

$(30)$

dek ngunanggi $\quad$ kaduk

camp south.western.bank DIST

'the place is on the southwest side, over there'

(DH12_V36_03.194)

(31) Speaker orientation and gesture for (30)

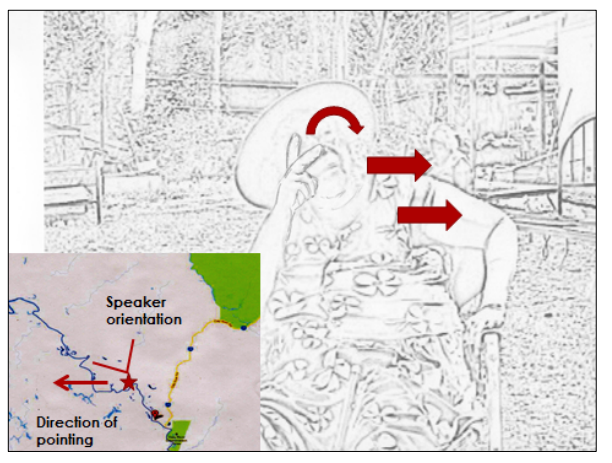

In line with (30) above, (32) also illustrates the use of kaduk and keen in larger scale spatial descriptions. The speaker explains the direction of the river flow during outgoing and incoming tides. The choice of keen to denote the outgoing tide might be interpreted in terms of a stereotypical or default situation since the turn of the tides is not realized during the wet season when the water always flows from the TopEnd towards the sea. Kaduk is also used less frequently than keen ${ }^{7}$. As a result, this might be accounted for by Levinson's pragmatic M-Principle stating that a marked expression (kaduk) indicates a non-stereotypical event/situation and an unmarked one (keen) the stereotypical one (Levinson, 1983: 136-137).

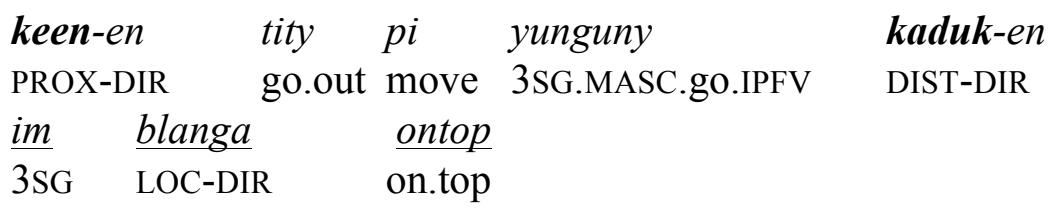

'the water goes out (towards the sea in outgoing tide) and it goes to the Topend over there (when the tide is coming in)' (DH12_A05_01_0148)

Adding to this kind of interpretation is an explanation offered by a speaker associating keen with the dangid wind direction and kaduk with the nul direction of the wind at the beginning of June when a strong dangid wind was blowing

\footnotetext{
${ }^{7}$ In a search of 33 recordings, kaduk was found 62 times in 61 annotations. Keen on the other hand occurred 246 times in 237 annotations in the same number of recordings. While this is not a representative or systematic sample, the numbers indicate a usage preference for keen based on functionality.
} 


\section{Mapping Worlds: Frames of Reference in MalakMalak}

during the recording session making this the unmarked and (at the time) dominant wind direction. In light of these two observations, the meaning of the terms then becomes directly associated with climatic, cultural, and landscape features of the speakers' environment.

\section{Conclusions}

Notably, the absolute terms based on prevailing wind directions are only used in orientation settings, but never in absolute FoR of the type 'the chair is nul of the ball'. Additionally, my corpus so far only revealed one example where the terms based on the course of the sun may be interpreted as absolute FoR ("the chair is to the east of the ball').

While the spatial terms elimirri/angundu and jalmiyen/yanbarr for horizontal direction may be used for both intrinsic and relative settings interchangeably, only the latter (albeit rarely) allow for orientation setting. For vertical direction, there is a clear distinct use of terms for absolute and intrinsic settings.

(33) Spatial terms and FoR usage

\begin{tabular}{|l|l|l|l|l|l|l|l|}
\hline Spatial term & Translation & \multicolumn{4}{|l|}{ Type of FoR } \\
\hline & & I & R & A & O & D \\
\hline dangid/nul & southeasterly/northwesterly wind & $\mathrm{X}$ & $\mathrm{X}$ & $\mathrm{X}$ & $\sqrt{ }$ & $\mathrm{X}$ \\
\hline miri jalk/miri baiga & west/east & $\mathrm{X}$ & $\mathrm{X}$ & $(\sqrt{ })$ & $\sqrt{ }$ & $\mathrm{X}$ \\
\hline elimirri/angundu & in front/behind & $\sqrt{ }$ & $\sqrt{ }$ & $\mathrm{X}$ & $\mathrm{X}$ & $\mathrm{X}$ \\
\hline jalmiyen/yanbarr & right/left & $\sqrt{ }$ & $\sqrt{ }$ & $\mathrm{X}$ & $(\sqrt{ })$ & $\mathrm{X}$ \\
\hline kanjuk/puyunduk & on top/underneath & $\mathrm{X}$ & $\mathrm{X}$ & $\sqrt{ }$ & $\sqrt{ }$ & $\mathrm{X}$ \\
\hline karrarra/jalk & down/up & $\sqrt{ }$ & $\mathrm{X}$ & $\mathrm{X}$ & $\mathrm{X}$ & $\mathrm{X}$ \\
\hline ngunanggi/kinangga & $\begin{array}{l}\text { southwestern river bank/the other } \\
\text { side/that side }- \text { northeastern river } \\
\text { bank/this side }\end{array}$ & $\mathrm{X}$ & $\mathrm{X}$ & $\sqrt{ }$ & $\sqrt{ }$ & $\sqrt{ }$ \\
& that side/this side & $\mathrm{X}$ & $\mathrm{X}$ & $\mathrm{X}$ & $\sqrt{ }$ & $\sqrt{ }$ \\
\hline ngunangga/kinanggi & there/here & $\mathrm{X}$ & $\mathrm{X}$ & $\mathrm{X}$ & $\mathrm{X}$ & $\sqrt{ }$ \\
\hline ngun/ki & 'over there'/over here' & $\mathrm{X}$ & $\mathrm{X}$ & $\mathrm{X}$ & $\sqrt{ }$ & $\sqrt{ }$ \\
\hline kaduk/keen & & & & & \\
\hline
\end{tabular}

\footnotetext{
${ }^{8}$ The abbreviations in this column are as follows: I 'intrinsic FoR'; R 'relative FoR'; A 'absolute FoR'; O ‘orientation'; D ‘direct FoR/deixis'
} 


\section{Dorothea Hoffmann}

I argued that the boundary-type terms kinangga/ngunanggi, may be used in absolute as well as deictic readings. The fundamental difference between these terms and their related counterparts ngunangga and kinanggi lies in an analysis including the deictic suffixes $-n g g i$ and $-n g g a$ as denoting orientation towards and away from the deictic center respectively. Additionally, while all these terms crucially entail a type of boundary located between the speaker and the figure, $n g u n$ and $k i$ only denote distal and proximal location in relation to a deictic center regardless of interference or specific location, but in terms of person-reference and visibility constraints.

Finally, kaduk and keen are accompanied by pointing or a specifically expressed spatial term. While keen depicts the location of figures in relative proximity to the speaker, kaduk is reserved for more distant locations. However, distance is clearly not such a relevant factor in distinguishing these terms as is person-based deixis with keen referring to the $1^{\text {st }}$ person (speaker) and kaduk to the $2^{\text {nd }}$ person (addressee) as seen in smaller scale descriptions.

Interestingly, while there are many named places used in spatial reference, there are no 'ad-hoc' landmarks of the kind 'the man is looking at that rock' attested in the data so far. This observation is in line with results from wordlist elicitations showing a lack of generic landscape terms which has also been observed for other languages such as Lao (Enfield, 2008) and Yélî Dnye (Levinson, 2008). Consequently, there is a culturally significant usage pattern for toponyms.

So far, this analysis of Frames of Reference in MalakMalak leaves a number of questions unanswered. Future research aims to include a broader discourse sample and to conduct a more fine-grained gestural analysis. Additionally, it is worthwhile exploring whether there is a semantically or morphosyntactically distinguishable difference between landmark-based and cardinal-type directionals. Including, an analysis of usage patterns could reveal important insights into the relationship between directions and places, directionals and toponyms in small- as well as large-scale descriptions.

\section{References}

Anderson S.R. and Keenan E.L. (1985) Deixis. In: Shopen, T. (ed) Language typology and syntactic description. Cambridge: Cambridge University Press, 259-308.

Barlew J. (2016) Anchored to what? An anaphoric approach to frames of reference. The 39th Annual Meeting of the Berkeley Linguistic Society. The University of California, Berkeley: Berkeley Linguistic Society.

Bickel B. (2001) Deictic Transposition and Referential Practice in Belhare. Journal of Linguistic Anthropology 10: 224-247.

Birk D.B.W. (1976) The Malakmalak Language of Daly river (Western Arnhem Land), Canberra: Pacific Linguistics. 


\section{Mapping Worlds: Frames of Reference in MalakMalak}

Bohnemeyer, J. (2013) Frames of reference in language, culture, and cognition: The Mesoamerican evidence. Plenary given at The 39th Meeting of the Berkeley Linguistic Society, The University of California, Berkeley: Berkeley Linguistic Society.

Bohnemeyer, J. and O'Meara, C. (2012) Vectors and frames of reference: Evidence from Seri and Yucatec. In: Filipovic L and Jaszczolt KM (eds) Space and Time in Languages and Cultures. Language, Culture and Cognition. Amsterdam/Philadelphia: John Benjamins Publishing Company, 217-250.

Bohnemeyer, J. and Perez Baez, G. (2008) MesoSpace. Spatial language and cognition in Mesoamerica: 2008 Field Manual.

Burenhult, N. (2008) Spatial coordinate systems in demonstrative meaning. Linguistic Typology 12: 99-142.

Danziger, E. (1994) Out of sight, out of mind: person, perception, and function in Mopan Maya spatial deixis. Linguistics 32: 885-907.

Danziger, E. (2003) Deixis, Gesture and Spatial Frame of Reference. CLS 39. 2nd ed. The University of Chicago: Chicago Linguistic Society 105-122.

Danziger, E. (2010) Deixis, Gesture and Cognition in spatial Frame of Reference Typology. Studies in Language 34: 167-185.

Dixon, R.M.W. (2003) Demonstratives: A cross-linguistic typology. Studies in Language 27: 62-112.

Enfield, N.J. (2003) Demonstratives in space and interaction: Data from Lao speakers and implications for semantic analysis. Language 79.

Enfield, N.J. (2008) Linguistic categories and their utilities: The case of Lao landscape terms. Language Sciences 30.

Hank, W.F. (1990) Referential Practice: Language and lived space among the Maya, Chicago: University of Chicago Press.

Haviland, J.B. (1993) Anchoring, Iconicity and Orientation in Guuguur Yimithirr Pointing Gestures. Journal of Linguistic Anthropology 3: 3-45.

Hoffmann, D. (2011) Descriptions of Motion and Travel in Jaminjung and Kriol. unpublished $\mathrm{PhD}$ dissertation: University of Manchester.

Koops, C. (2013) Direction and Location in Cherokee Deictic Prefixes. Paper given at The 39th Annual Meeting of the Berkeley Linguistic Society. The University of California, Berkeley: Berkeley Linguistic Society.

Levinson, S.C. (1983) Pragmatics, Cambridge: Cambridge University Press.

Levinson, S.C. (1996) Frames of Reference and Molyneux's question: crosslinguistic evidence. In: Bloom P, Peterson MA, Nadel L, et al. (eds) Language and Space. Cambridge, MA: MIT Press.

Levinson, S.C. (2003) Space in Language and Cognition. Explorations in Cognitive Diversity, Cambridge: Cambridge University Press.

Levinson, S.C. (2008) Landscape, seascape and the ontology of places on Rossel Island, Papua New Guinea. Language Sciences 30: 256-290.

Levinson, S.C., Brown P., Danziger E., et al. (1992) Man and Tree \& Space Games. In: Levinson SC (ed) Space stimuli kit 1.2: November 1992. Nijmegen: Max Planck Institute for Psycholinguistics, 7-14.

Pederson, E., Danziger E., Wilkins D., et al. (1998) Semantic Typology and Spatial Conceptualisation. Language 74: 557-589.

Schultze-Berndt, E. (2006) Sketch of a Jaminjung Grammar of Space. In: Levinson SC and Wilkins DP (eds) Grammars of Space. Cambridge: Cambridge University Press, 63-113. 


\section{Dorothea Hoffmann}

Stanner, W.E.H. (1933) The Daly River tribes. A report on fieldwork in North Australia. Oceania III and IV.

Terrill, A. and Burenhult, N. (2008) Orientation as a strategy of spatial reference. Studies in Language 32: 93-136.

Dorothea Hoffmann

University of Chicago

Department of Linguistics

1010 E $59^{\text {th }}$ Street

Chicago, IL 60357

hoffmann.dorothea@gmail.com 